\title{
Results from Finland's 2018 Report Card on Physical Activity for Children and Youth
}

\author{
Katariina Kämppi, Annaleena Aira, Nina Halme, Pauliina Husu, Virpi Inkinen, Laura Joensuu, \\ Sami Kokko, Kaarlo Laine, Kaisu Mononen, Sanna Palomäki, Timo Ståhl, \\ Arja Sääkslahti, and Tuija Tammelin
}

\section{Introduction}

Finland's 2018 Report Card was prepared as part of the Global Matrix 3.0 (Figure 1). It was the third assessment of physical activity (PA) for Finnish children and adolescents (previous years 2014 and 2016). The purpose of this abstract is to summarize the results of Finland's 2018 Report Card and provide grades for 10 indicators concerning the status and promotion of PA among Finnish school-aged children and youth.

\section{Methods}

Finland's 2018 Report Card included the 10 core PA indicators that are common to the Global Matrix 3.0 (Table 1). The data sources were most recent national monitoring and surveys related to PA including the LIITU study (2016), the School Health Promotion (SHP) Study (2017), National Move! monitoring system for physical functioning capacity 2017 and Promotion of PA in municipalities - TEAviisari 2016. Finland's 2018 Report Card work group included 19 specialists from different fields, working on research, policy or practices related to PA among children and adolescents. Grades and rationales for Finland's 2018 Report Card are presented in Table 1.

In addition to the Global Matrix 3.0 process concerning school-aged children (7-15 years old in Finland), the Finnish work group gathered the data for children and adolescents in four categories: 0-6 years old, 7-12 years old, 13-15 years old and 16-18 years old. These results are presented in Finland's national Report Card.

\section{Results and Discussion}

Compared to Finland's last assessment of PA for children and adolescents in 2016, seven indicators in the 2018 Report Card were graded as slightly better (Organized Sport Participation, Active Play, Active Transportation, Family and Peers, School, Community and the Built Environment, Government Strategies and Investments). Overall PA remained unchanged from the previous assessment (grade of D) and sedentary behaviours was graded D-, which is slightly lower than D in 2016. Physical fitness was a new indicator in the Global Matrix 3.0 and it was graded C in Finland.

\section{Conclusion}

Governmental support for PA promotion among school-aged children and youth in Finland during past few years has been stronger than ever before. Nevertheless, the proportion of Finnish children and youth who achieve the recommended levels of daily PA and screen time is still low. Facilitating a population level change in PA among children and youth requires wide collaboration and contribution of different sectors and actors. Everyone working with children and adolescent and influencing their lives has an opportunity to facilitate their PA. In addition, more effective interventions, operation models, concrete tools as well as

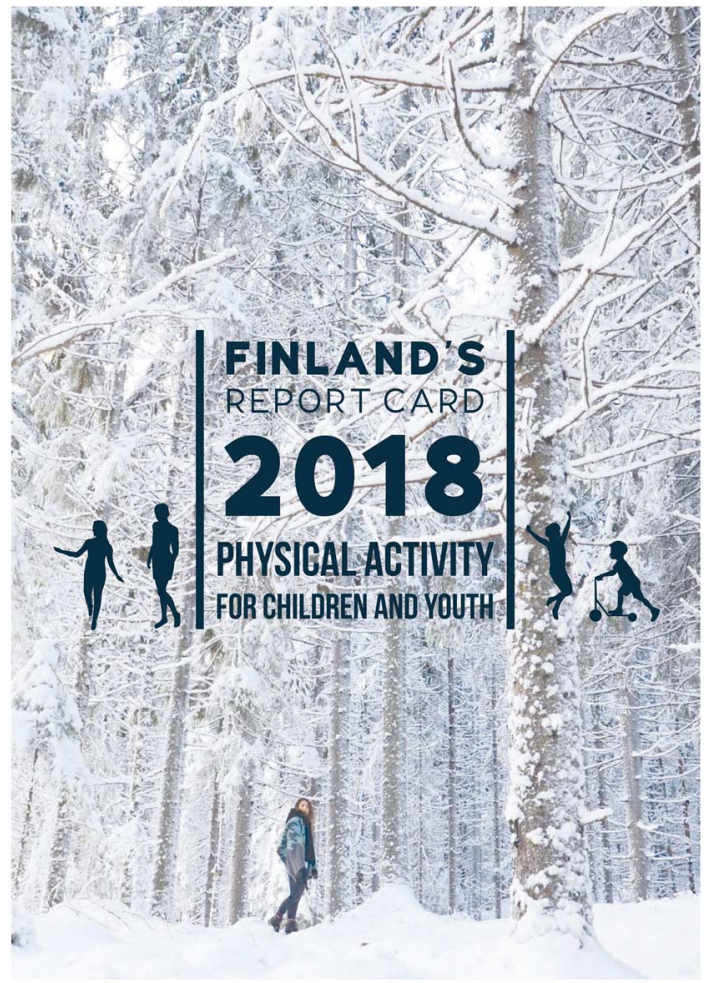

Figure 1 - Finland's 2018 Report Card cover.

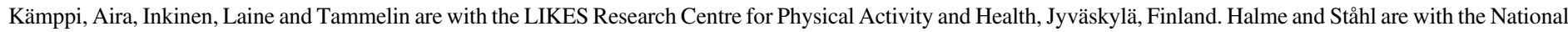

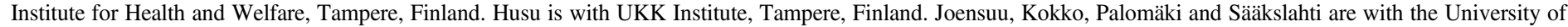

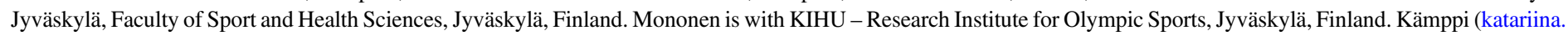
kamppi@likes.fi) is the corresponding author. 
Table 1 Grades and rationales for Finland's 2018 Report Card

\begin{tabular}{|c|c|c|}
\hline Indicator & Grade & Rationale \\
\hline $\begin{array}{l}\text { Overall Physical } \\
\text { Activity (PA) }\end{array}$ & $\mathrm{D}$ & $\begin{array}{l}\text { The proportion of children and adolescent who meet the minimum recommendation of engaging in at least } \\
60 \text { minutes of PA a day. } 34 \% \text { of } 9-15 \text { y (LIITU objective measurements, 2016), 31\% of 9-15 y (LITTU survey } \\
2016) .{ }^{1} 45 \% \text { of } 10-11 \text { y and } 19 \% \text { of } 14-15 \text { y (School Health Promotion (SHP) Study 2017). }{ }^{2}\end{array}$ \\
\hline $\begin{array}{l}\text { Organized Sport } \\
\text { Participation }\end{array}$ & $\mathrm{C}+$ & $\begin{array}{l}\text { The proportion of children and youth who participate in sports club activities or other organized physical activities. } \\
62 \% \text { of } 9-15 \text { y participate in sports club activities (LIITU survey 2016). } 53 \% \text { of } 9-15 \text { y participate in sports club } \\
\text { activities at least once per week (LITU survey 2016). }{ }^{1} 48 \% \text { of } 14-15 \text { y participate in organized physical activities } \\
\text { (School Health Promotion (SHP) Study 2017). }{ }^{2}\end{array}$ \\
\hline Active Play & $\mathrm{C}$ & $\begin{array}{l}\text { The proportion of children and youth who engage in unorganized active play at least } 4 \text { times per week. } 51 \% \text { of 9- } \\
15 \text { y participate in unorganized PA at least } 4 \text { times per week (LITU survey 2016). }{ }^{1} 41 \% \text { of } 14-15 \text { y participate in } \\
\text { unorganized physical activity or sports almost daily (School Health Promotion (SHP) Study } 2017 \text { ). }{ }^{2}\end{array}$ \\
\hline Active Transportation & $\mathrm{B}+$ & $\begin{array}{l}\text { The proportion of children and adolescent who actively commute to school, on foot or by bike (among those who } \\
\text { live less than } 5 \mathrm{~km} \text { away from school). Total } 77 \% \text { of } 9-15 \mathrm{y}(80 \% \text { of } 9 \mathrm{y}, 83 \% \text { of } 11 \mathrm{y}, 79 \% \text { of } 13 \mathrm{y}, 61 \% \text { of } 15 \mathrm{y} \text {, } \\
\text { LIITU survey 2016). }\end{array}$ \\
\hline Sedentary Behaviours & D- & $\begin{array}{l}\text { The proportion of children and adolescent who meet recommendations related to screen time (maximum of two } \\
\text { hours) on at least } 5 \text { days per week } 25 \% \text { of } 9-15 \text { y (LIITU survey 2016). }{ }^{1}\end{array}$ \\
\hline Physical Fitness & $\mathrm{C}$ & $\begin{array}{l}\text { Average percentile achieved: BOYS C- }(44 \% \text { of } 11 \text { and } 14 \mathrm{y}, 46 \% \text { of } 11 \mathrm{y}, 41 \% \text { of } 14 \mathrm{y}) \text {, GIRLS C+ (59\% of } 11 \text { and } \\
14 \mathrm{y}, 49 \% \text { of } 11 \mathrm{y}, 69 \% \text { of } 14 \mathrm{y} \text { ) reached by using VO2peak (Median values used instead of mean values). (National } \\
\text { Move! monitoring system for physical functioning capacity } 2017){ }^{3}\end{array}$ \\
\hline Family and Peers & B- & $\begin{array}{l}\text { The proportion of children and adolescents with family members or peers who encourage and support them to be } \\
\text { physically active or are physically active with them. The percentage of } 9-15 \text { y report that at least one parent: } \\
\text { encourages them to be physically active }(80 \%) \text {, contributes financially to their children's physical activities ( } 79 \% \text { ), } \\
\text { takes them to venues of physical activities }(64 \%) \text {, is physically active with their children (38\%). (LIITU survey } \\
\left.2016) .{ }^{1} 43 \% \text { of } 9-15 \text { y note that their friends are physically active with them (LIITU survey } 2016\right) .{ }^{1}\end{array}$ \\
\hline School & $\mathrm{A}$ & $\begin{array}{l}\text { The proportion of schools participating in the national Finnish Schools on the Move programme (FSM). } 87 \% \text { of } \\
\text { comprehensive schools in Finland 4/2018 (Finnish Schools on the Move register, LIKES). }{ }^{4} \text { FSM is a national action } \\
\text { programme aiming to achieve more pleasant and active schooldays. Programme encourages schools to increase PA } \\
\text { during school day and during commuting. https://liikkuvakoulu.fi/sites/default/files/lk_valiraportti_111017_en.pdf }\end{array}$ \\
\hline $\begin{array}{l}\text { Community and } \\
\text { Environment }\end{array}$ & $\mathrm{B}+$ & $\begin{array}{l}\text { The proportion of municipalities that covered the promotion of PA in the municipal strategy and had special support } \\
\text { for childrens' and adolescents' physical activities. } 73 \% \text { of municipalities covered the promotion of PA in their } \\
\text { strategy, } 84 \% \text { of municipalities defined goals to the promotion of PA among children and adolescents, } 81 \% \text { of } \\
\text { municipalities defined resources to the promotion of PA among children and adolescents, } 62 \% \text { of municipalities } \\
\text { provided school gyms free of charge for the use of sports clubs for children and adolescents, } 76 \% \text { of municipalities } \\
\text { provided free practice session at sports grounds and ball fields for children and adolescents (Promotion of PA in } \\
\text { municipalities 2016). }{ }^{5}\end{array}$ \\
\hline Government & A- & $\begin{array}{l}\text { The government creates conditions and provides opportunities for realising the goals set in its sports and PA policy } \\
\text { by providing resources for PA services for children and adolescents. Core curricula in basic education supports } \\
\text { physically active way of learning, national programme exists to promote physically active school day, and the } \\
\text { monitoring system of physical functional capacity (Move!) has been implemented for all students aged } 11 \text { and } 14 \text {. }\end{array}$ \\
\hline
\end{tabular}

environmental solutions are needed to support the change toward more physically active childhood and youth.

\section{References}

1. Kokko S, Mehtälä A, eds. The Physical Activity Behaviours of Children and Adolescents in Finland. Results of the LIITU study. Publications of the National Sports Council; 2016:4.

2. School Health Promotion (SHP) study. 2017. https://thl.fi/fi/web/lapsetnuoret-ja-perheet/tutkimustuloksia. [in Finnish].Accessed June 15, 2018.
3. National Move! monitoring system for physical functioning capacity. 2017. https://www.edu.fi/move/english. Accessed June 15, 2018.

4. Finnish Schools on the Move -register. Registered Schools in Finland. https://app.powerbi.com/view?r=eyJrIjoiODFmNDhhNmUtMDA0M C00YWY3LWFmNzQtOGY4YWNmZDAxYzczliwidCI6IjA3Mjlm NzA0LTIwMTktNGY2ZC05MmU0LTMzNjdiMmRhOWMxMSIs ImMiOjh9. [in Finnish].Accessed April 27, 2018.

5. Promotion of physical activity in municipalities. 2016. https://www. teaviisari.fi/teaviisari/en/index. Accessed June 15, 2018. 